EPiC Series in Language and Linguistics
Volume 1, 2016, Pages 283-297
CILC2016. 8th International
Conference on Corpus Linguistics

\title{
A Corpus-Attested View of Business English Metaphors
}

\author{
Marija Milojkovic \\ University of Belgrade, Belgrade, Serbia \\ marija.milojkovic@fil.bg.ac.rs
}

\begin{abstract}
Louw's (2009) idea to create a corpus-attested dictionary of literary terms may initially involve analysing uncontested examples of irony, antithesis and the like, in corpus terms. The paper analyses non-literal expressions in a Guardian business text against the background of the corpus-attested definition of metaphor, arrived at through the detailed analysis of two metaphors in Yeats's 'The Circus Animals' Desertion' by means of Louw's Contextual Prosodic Theory (CPT) (Milojkovic 2016). Given that the delexical expressions in the Guardian text are not meant to convey any meanings other than explicit, and that their relexicalisation may be achieved only through other delexical expressions, the paper suggests that they be called delexical rather than metaphorical.
\end{abstract}

\section{Preamble}

Louw (2009) calls for a corpus-attested glossary of literary terms. While the realisation of this idea is certainly overdue at a time when reference corpora may be held to achieve the proper degree of balance and representativeness, certain issues need clarifying before actual research is presented and defended by argumentation.

Contextual Prosodic Theory, developed by Louw, is a rounded theory that takes into account both lexis and grammar. While its beginnings go back to Sinclair's work in Cobuild, and he was the first to notice both the phenomena of delexicalisation and semantic prosody, Louw's efforts have always been aimed at interpreting a particular stretch of text against the backdrop of reference corpora, and in this way have brought about the beginning of corpus stylistics as a discipline. This approach demands great sensitivity as it deals with contextual nuances on a scale that does not seem achievable in the fields of corpus linguistics and computational linguistics generally. The large scale of the big data cannot be analysed without perpetual contact with the small, and sometimes minute, scale of contexts, both inside the studied text and in the reference corpus, where each instantiation of a pattern will have its contextual justification. The work is so delicate that perfection does not seem achievable; yet, the 
context-pattern connection is a vital link which should, in theory, prove to be the one completing the investigations conducted both in stylistics and in corpus linguistics.

In practice, the approach sees meaning inherent in contextualised patterns. Meaning is the ultimate goal of all language practice, although some relativist pragmatic approaches see it as practially inconveyable (e.g. LaPolla 2006). If we take meaning as the expression of content, it must at the moment of creation bear strictly individual character. As such, how can it be justifiably interpreted through reference corpora? It has been the practice of Contextual Prosodic Theory (Bill Louw, personal communication, but my paraphrase) to resort to philosophers of language, should common sense fail to convince. Godel's theorem (Mautner, 2005: 248) states quite clearly that a system cannot interpret itself within itself. According to Louw (personal communication), that should not be true of language as a whole, precisely because a large enough reference corpus, ideally representative of its language, will in most cases (except where events are very rare) yield plentiful data for interpretation. Still, that is not true of a particular context, which is never and has never been interpreted within itself - and here we resort to common sense. Any stretch of text is interpreted by its recipient via its juxtaposition with the recipient's accumulated experience of that language, contained, to put it crudely, in that person's head. How, then, is this process different in its essence from comparing a stretch of text against a large and representative corpus? Essentially, both interpretations involve a database of sorts, and this is where Godel is helpful. Therefore, the additional tool in the shape of a corpus can only enhance our interpretation, with its advantageous multitude of pattern instantiations and contexts.

The issue of pattern interpretation, then, is settled, and this will be of interest to stylisticians and literary critics. What of corpus linguistics and computational linguistics? Contextual Prosodic Theory, insisting on Firth's context of situation, must of necessity modify the findings produced by the big data. Moreover, the context in question must not be limited to co-text. Here again, Godel's theorem proves of use. A narrow context cannot, and in reality never is (bar unusual exceptions) taken at its face value without macro-context of situation. Thus, Godel's principle works both for language patterns and the distinction between co-text, context and macro-context of situation.

This ideally envisaged cooperation between the fields of corpus stylistics, corpus linguistics and computational linguistics has not fully materialised. Unlike the discipline of stylistics, which has accepted Louw's innovations (Simpson, 2014), corpus linguistics has so far produced only very flawed and bafflingly incompetent descriptions of semantic prosody alone. Leaving aside the still uncorrected view presented by McEnery and Hardie (2012), Dominic Stewart's book (2010) is a good illustration of how a linguist, without proper awareness of the importance of context, handles the 'concept' of semantic prosody. Corpus linguists may have been misunderstanding the scope and impact of semantic prosody (SP) due to the fact that they are not, broadly speaking, stylisticians: they are unused to the detailed study of a particular text. This has led to the most trivial errors in judgement, which almost do not deserve a serious mention. Stewart (2010: 23), in his discussion of the negative prosody of 'cause', offers the following context from the BNC:

The door closed and then Elaine pulled the magazine in, causing the letter box to snap shut smartly.

Stewart proceeds: 'Here once again it seems problematic to postulate that some sort of attitude is being expressed, because it is not clear of whom or of what the respective speakers/writers might disapprove. Of letter boxes? Of Elaine?' It does not occur to the author to check the semantic prosody of 'snap' and find out that it just might, in the reference corpus, warrant the use of 'cause' in authorial text.

The list of such examples is long, and they would have been chalked down to the obvious necessity of a trial and error stage whenever a new theory is presented to the academic community, had they not apparently led very serious researchers to pronounce the idea of 'text reads text' a mantra 
(Xiao 2013). Nevertheless, the very fact that corpus linguists have approached the subject of SP (e.g. Hunston 2007; McEnery and Hardie 2012) signifies that it is within the scope of corpus linguistics as much as of stylistics (as a corpus stylistics theory should be).

This preamble started with the idea that Louw's Contextual Prosodic Theory (CPT) takes into account both lexis and grammar. What corpus linguistics has, unaccountably in my view, been neglecting (though it is better to ignore an area altogether than give incomplete accounts of it) is the development of a phenomenon related to semantic prosody, namely, corpus-derived subtext of grammatical strings. Corpus-derived subtext, or the most frequent lexical variables within a grammar string (named quasi-propositional variables [QPVs]), together with other phenomena taken into account by CPT (such as relexicalisation, SP, states of affairs, similar events, context of situation and context of culture) has a function in pinpointing developments in texts that can only be exposed through reference corpora. However, in addition to being opaque to intuition, subtext may prove a challenge to research because it might show different degrees of participating in constructing a text's meaning. While it has been shown (Louw and Milojkovic, 2014) that in a poem, as a concise thoughtthrough form, the role of subtext is as crucial as it is subtle, the same may not apply to texts written after less contemplation or with a different kind of motivation. As this paper proposes to tackle business English, these differences may surface in the process of research.

While bringing together a corpus approach and a strictly stylistic approach in the attempt to provide literary and stylistics terminology with empirically derived corpus-attested definitions, one must not forget the influence of cognitive studies, especially when it comes to metaphor. This paper does not propose to comment on this area of study, which has undoubtedly yielded interesting insights. However, I believe that the revolution caused by Lakoff and Johnson (1980), who proposed to label any non-literal use of an expression 'metaphorical', even in cases where its literal use may be much rarer in the corpus, is not helpful enough in investigating the nuanced literal-delexicalrelexicalised continuum of actual language. One may or may not visualise actual expressions that are generally used non-literally, as the visualisation aspect must be strictly individual. The argument that they can be visualised is of little help in actual meaning construal, which always involves interdependent context clues, whose relationship is always unique.

One final issue has to do with the labelling of this relationship, whose outcome will turn out to constitute metaphor, irony, simile etc. If we adopted a strictly empirical bottom-up approach, we would study a long stretch of text, connecting each co-text (Sinclair's dynamic nine-word window seems a plausible start) with its wider contexts, on the one hand, and its language pattern with the patterns in the reference corpus and their respective contexts. Each such transition in the text would then need to be labelled differently, until similar transitions emerge that deserved a label already awarded. One wonders what labels would be appropriate; but do we keep the old ones, such as 'metaphor'? If yes, we might be entering circular reasoning: 'I accept that the transition described is a metaphor, because I know what metaphor is, and yet I do not know what metaphor is because the definition of metaphor that I have learnt as part of my education has never been corpus-attested'. Still, it would be too confusing to introduce a completely different range of terms. Therefore, the approach adopted in this paper accepts that there is a type of transition conventionally known as metaphor (see established glossaries of literary terms, e.g. Abrams and Harpham (2009) or Cudden, J. A. (1999)). These unquestionable transitions should be corpus-attested first, and it is against these that different other transitions should be measured, with certain similarities or differences recorded. Should this approach prove a success, the same procedure will be adopted regarding examples of other wellknown types of transition (e.g. irony), with the intermediary types of transition recorded as one goes along.

As a starting point, this paper proposes to adopt the corpus-attested definition of metaphor that grew out of the detailed study of two metaphors (see the traditional sources quoted above) in the poem by W. B. Yeats 'The Circus Animals' Desertion' (Louw and Milojkovic 2014; Milojkovic 2016). Despite the minimal number of metaphors studied (two) and their coming not only from the same 
author but also from the same short text, the advantage of the procedure lay in the fact that both metaphors had the same implied meaning and, moreover, their corpus-derived subtext (as defined above) overlapped to such a considerable degree that it cannot have been accidental precisely because of the source of the poem and its authorship. This paper further proposes to investigate a business English text and see if any of the non-literal usages in it fit in with this corpus-attested definition. If so, these usages will be pronounced metaphorical. If not, these transitions will be given corpusattested description/descriptions, and the differences between them and Yeats's metaphors will be noted.

A short recapitulation of how the corpus-attested definition of metaphor based on Yeats's poem was arrived at (Milojkovic 2016) is in order. 'The Circus Animals' Desertion' contains two metaphors referring to the same target. Here they are, embedded in their respective grammar strings: 'My circus animals were all on show' (Stanza 1), and 'Now that my ladder's gone' (Stanza 5). Both metaphors, one in the first stanza and one in the coda, refer to the same implied meaning, which can be described as 'literary devices', in the broad sense; or, if we abandon all inference, to whatever the poet has lost. Although the grammar strings in both metaphors are very different ('my * were all' vs. 'now that my * is' co-selected with 'gone'), the subtext in both is very similar. Not only is there a general aura of significance, but it contains, in both cases, a consistent group of the QPVs (most frequent lexical variables, as explained above) denoting a significant person, like a family member, for example. Relexicalisation (the regaining by a delexical word of its full lexical meaning because of its proximity with another collocate) is present in both cases: as in happens, both the 'circus animals' in Stanza 1 and the 'ladder' in Stanza 5 appear in the vicinity of a full list of entities or objects that re-create their respective worlds (that of the circus in Stanza 1 and that of the rag-and-bone shop in Stanza 5). The implied meaning of these metaphors is confirmed by co-selection: we can co-select 'device*' with 'theme' ('theme' being the issue under discussion in stanza 1, and, indeed, the whole poem) and find a single context from literary criticism in the BNC, and five contexts in COCA, in which those of artistic creation predominate. These examples prove that the semantic auras of grammar strings interact within the poem in such a way as to lead to the following corpus-attested definition of 'original' metaphor (the term 'original' is here to satisfy the followers of Lakoff and Johnson (1980)):

An 'original' metaphor consists of a grammatical string containing a lexical item unique for the string in question (not found in the reference corpus).

The lexical item will interact with the surrounding context clues in two ways:

- relexicalisation will allow it to attain its literal meaning in the text and the reference corpus

- co-selection will allow it to attain a second, provisional meaning in the text, which is the purpose of the metaphor; the states of affairs chunked in the reference corpus by co-selection will confirm this

The most frequent lexical items of the grammatical string in question (its subtext) will represent a third, hidden meaning. They will interact with the context clues in ways which will support the existence of the hidden meaning.

The paper will take up the question of whether and to what extent this definition is applicable to any non-literal usages in a particular chosen business English text printed in a Guardian online edition. 


\section{Non-literal usages in the chosen Guardian business text}

\subsection{Aims}

This section will be devoted to the study of all non-literal usages found in the Guardian text, quoted in full below. The aim of the study will be to a) ask if and to what degree the mechanisms underlying these usages overlap with those noted in the study of the two metaphors by Yeats namely, in the domain of relexicalisation, co-selection, and subtext, and b) to offer a generalised definition of these usages, comparable to that of metaphor offered in the case of Yeats. Moreover, a useful question to ask in this context is whether the grammatical strings are as interconnected in the studied text as they are in Yeats's poem, where all grammar strings unite to convey a meaning (see Louw and Milojkovic (2014) for a detailed analysis of the whole poem's subtext).

\subsection{Subtext in non-literal usages in the chosen Guardian text}

As it is the stated goal of the paper to compare the two metaphors by Yeats with those of a Guardian text, a few words must be said regarding authorial intention. 'A Circus Animals' Desertion' is clearly an autobiographical poem, where the persona, without any attempts at disguise, experiences writer's block. Still, the subtext of the grammatical strings underlying both metaphors points to a significant person. Be that as it may, it was not Yeats's authorial intention to write a confessional to the nation, clearly and unambiguously describing his personal distress. In part, while describing it, his aim was also to obfuscate, to show 'through a glass darkly', and not 'face to face'. Ambiguity and obfuscation is certainly not the aim of the Guardian text in question:

\section{UK retail sales drop as shoppers cut back on food and clothes}

Katie Allen

Britain's retailers have been hit by a sharp drop in sales as shoppers cut back on food and clothes in the latest sign households are nervous about the economic outlook.

The Office for National Statistics (ONS) said retail sales volumes decreased $1.3 \%$ last month, a much sharper drop than the $0.1 \%$ dip forecast by economists in a Reuters poll. Sales were up $2.7 \%$ on the year, well below forecasts for $4.4 \%$ growth.

Statisticians said the main drag came from food and clothing, echoing other reports that fashion sales had suffered from unsettled weather while the early Easter had done little for grocers.

The data will fan fears that the UK economy has lost momentum in the face of a slowdown in global trade and as domestic spending is dented by uncertainty before June's referendum on EU membership. The first official snapshot of UK GDP growth in the opening quarter is to be released next week.

David Kern, chief economist at the British Chambers of Commerce (BCC), said March's sharp drop in retail sales was disappointing.

"These figures reinforce our view that UK economic growth slowed in the first quarter of 2016," he said.

Consumer spending has been the main driver of UK economic growth, helped by high employment, rock-bottom interest rates and low inflation, but recent surveys suggest households

http://www.theguardian.com/business/2016/apr/21/uk-retail-sales-drop-shoppers-cut-back-food-clothes-ons highlighted chunks of text are those that were studied, the lexis highlighted in bold and the grammar strings underlined)

(the 
are getting a tighter hold on the purse strings as worries grow about the domestic and global economy.

"March's retail sales figures confirm that trading over the Easter holidays was unusually quiet, adding to evidence of a consumer slowdown," said Samuel Tombs, chief UK economist at the consultancy Pantheon Macroeconomics. "It is clear that the consumer recovery is losing pace."

But this month could bring some respite for retailers, Tombs added. "Sales likely will bounce

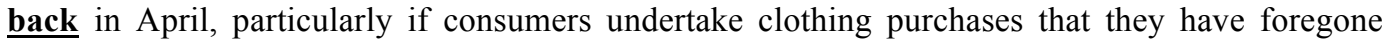
recently."

The ONS said clothing sales fell $2.3 \%$ on the month while household goods sales were down $2.9 \%$.

The less volatile figures for three months taken together also pointed to a slowdown. Sales volumes rose $0.8 \%$ in the first quarter on 2016 , down from growth of $1.0 \%$ in the final three months of 2015 .

In value terms, the amount spent at retailers in March was down $0.1 \%$ on a year ago and $1.3 \%$ from the month before.

The news from online sales was somewhat brighter. They were up $8.9 \%$ on the year but down $0.5 \%$ on the month.

The amount spent in the retail industry decreased by $0.1 \%$ compared with March 2015 and decreased by $1.3 \%$ compared with February 2016.

The ONS said average store prices fell by $3 \%$ on the year, the 21 st consecutive month of yearon-year price falls.

Against the backdrop of falling shop prices, and generally low inflation, the Bank of England has kept interest rates at a record low of $0.5 \%$. Kern said policymakers at the Bank should continue to sit tight on borrowing costs.

"The fact that store prices declined further in March confirms our assessment that overall inflationary pressures in the economy are still muted (look at BNC?), and strengthens the argument for the monetary policy committee to persevere with the current low level of interest rates for the time being to support the fragile recovery."

The official retail data chimes with industry figures earlier this month that also showed a weak March for retailers. The British Retail Consortium (BRC) said unsettled weather had hit demand for clothes while takings at grocers were hurt by lower food prices and Easter closures.

The BRC said like-for-like sales values fell $0.7 \%$ in March on a year earlier, the biggest drop since last August. Sales were flat on a year ago in total terms, which does not adjust for the effect of new store openings.

Let us focus on several instances of non-literal usage to show the developments in the text in more detail. The very first line will be particularly significant, because, according to Louw, first lines reveal prospection (Louw and Milojkovic, 2015; see also Milojkovic and Louw, 2016 for a study of prospection in English non-native academic essays). Prospection is the quality of subtext (it is, as explained above, the most frequent lexical variables of a grammar string, recoverable in the reference corpus) to point at later developments in texts. For example, a student's essay about the crucial role of gaining knowledge for its own sake in the process of education may start with the words 'As our society switches from rural to urban'. The subtext of this first line, recovered in the BNC (Davies, 2004-) and the Google Books - UK corpus (Davies, 2011-) proves to be 'as our knowledge advances'. It obviously prospects the contents of the essay (for an extensive analysis of this string's subtext see Louw and Milojkovic 2016). Let us look at the beginning of the text: 'Britain's retailers have been hit by a sharp drop in sales as shoppers cut back on food and clothes in the latest sign households are 
nervous about the economic outlook.' The grammatical string '*s have been * by' was analysed in the $\mathrm{BNC}$ and in the Google Books corpus. These are the first twenty five occurrences:

\begin{tabular}{|l|l|l|l|l|}
\hline & BNC & & Google Books UK & 2920 \\
\hline 1 & projects have been funded by & 4 & results have been obtained by & 1908 \\
2 & steps have been taken by & 4 & attempts have been made by & 1177 \\
3 & claims have been made by & 3 & efforts have been made by & 900 \\
4 & costs have been reduced by & 3 & observations have been made by & 739 \\
5 & flowers have been left by & 3 & experiments have been made by & 660 \\
6 & leaflets have been published by & 3 & results have been reported by & 648 \\
7 & problems have been compounded by & 3 & Attempts have been made by & 588 \\
8 & shots have been fired by & 3 & results have been confirmed by & 470 \\
9 & applications have been received by & 2 & steps have been taken by & 425 \\
10 & attempts have been made by & 2 & findings have been reported by & 400 \\
11 & 1980s have been marked by & 2 & contributions have been made by & 395 \\
12 & concerns have been expressed by & 2 & observations have been confirmed by & 367 \\
13 & contents have been approved by & 2 & discoveries have been made by & 332 \\
14 & costs have been cut by & 2 & improvements have been made by & 313 \\
15 & decisions have been made by & 2 & results have been achieved by & 308 \\
16 & efforts have been hampered by & 2 & findings have been confirmed by & 306 \\
17 & efforts have been made by & 2 & cases have been reported by & 306 \\
18 & emissions have been reduced by & 2 & pains have been taken by & 298 \\
19 & findings have been replicated by & 2 & arrangements have been made by & 289 \\
20 & findings have been reported by & 2 & additions have been made by & 269 \\
21 & frames have been funded by & 2 & things have been done by & 266 \\
22 & Indians have been killed by & 2 & books have been written by & 256 \\
23 & jobs have been created by & 2 & years have been marked by & 255 \\
24 & levels have been reduced by & 2 & measures have been taken by & 253 \\
25 & lives have been devastated by & 2 & works have been edited by & \\
\end{tabular}

The findings yielded by the corpora so far are not identical. The Google Books corpus shows an overall semantic aura of constructive activity, whilst the BNC does contain markedly negative variables: 'compounded', 'hampered', 'killed' and 'devastated'. The string 'flowers have been left by' in line 5 is particularly telling. The two lists of variables shown by Google Books have little to do with 'retailers' in the first slot, as they point to actions and their results ('findings', 'arrangements', 'measures') rather than people being harmed (although, in the studied text, 'retailers' stands for companies rather than actual people). On the other hand, harmed individuals appear in the BNC:

- in context 5, indirectly ('flowers have been left by')

- $\quad$ in context 8 ('shots have been fired by')

- $\quad$ in context 22 ('Indians have been killed by')

- in context 25 ('lives have been devastated by'; wider contexts show that 'devastated' implies harm but not death)

Mindful of Louw's notion of similar events, we will notice the following strings in the BNC corpus whose context of situation involves harm done to individuals/companies/communities: 'lives have been shattered by' ( 2 occurrences), 'camps have been attacked by (1 occurrence; death is part of the context of situation', 'buses have been damaged by' (1 occurrence, the next collocate is 'missiles'), 'areas have been ruined by' (1 occurrence, the next collocate is 'nuclear testing'). As for Google Books, the following events similar to the one studied in the original text may be noted in the whole corpus: 'crimes have been committed by' ( 92 occurrences), 'lives have been lost by' ( 91 occurrence), 'lives have been affected by' ( 80 occurrences), 'families have been ruined by' ( 76 occurrences), 'bodies have been shattered by' (69), 'murders have been committed by' (58), 'deaths have been caused by' (57), 'wars have been caused by' (48), 'fires have been caused by' (44), 'losses have been sustained by' (44), 'frauds have been committed by' (44), 'animals have been killed by' (43), 'losses have been caused by' (42). Harm inflicted in these contexts does tend to threaten or even take human lives. 
Let us look at another grammatical string enveloping a non-literal expression. In 'shoppers cut back on food and clothing', the string '*s * back on *' yields 79 occurrences in the Google Books, but the grammatical pattern (necessary to observe, because it is part of a larger grammatical whole) is followed by only three: 'days come back on me' (60 occurrences, all of them a quote by Lord Byron), and 'times look back on their share' (42, all a quote by Walter Scott), and 'soldiers fell back on every side' (40; one and the same quote by Edward Gibbon). Interestingly, death is part of the context of situation in all three cases:

1 Thou tomb! and other days come back on me

With recollected music, though the tone

Is changed and solemn, like the cloudy groan

Of dying thunder on the distant wind;

2 Think you not it is a sore trial for flesh and blood, to be called upon to execute the righteous judgements of heaven while we are yet in the body, and continue to retain that blinded sense and sympathy for carnal suffering, which makes our own flesh thrill when we strike a gash upon the body of another? And think you, when some prime tyrant has been removed from his place, that the instruments of his punishment can at all times look back on their share in his downfall with firm and unshaken nerves?

3 In a transport of despair his sister issued from the tent and adjured the general of the Cufians, that he would not suffer Hosein to be murdered before his eyes: a tear trickled down his venerable beard; and the boldest of his soldiers fell back on every side as the dying hero threw himself among them.

Additionally, Google Books US provides the following contexts:

- 'eyes were back on the' (112); only three contexts were actually recovered from the corpus, all of them describing an important transition:

"Okay, so your due date is the 19th of August, next year. But we'll book another ultrasound for a few months time, you can than find out the sex if you want?" Ariel's eyes were back on the screen and listening to the heart beat. "I don't care ifit's a boy or a girl, as long as it's healthy.

asks Paul, speakingfor the first time. "Yes," I answered, "and they all disappeared with the woman and the child the day before the storm." The Mute's eyes were back on the snow. "Now," said I, "I'll make you a rich man if you take me straight to the place where he's hiding.

His eyes were back on the newspaper. 'This about that nasty murder then?' 'Yes.' 'Hoping I'm your man, eh?' 'Enquiries are continuing.' 'Don't waste your precious time and resources on me. I'm not worth it.' He turned a page. 'Thanks for the advice,' said Lara.

- $\quad$ 'historians look back on the' (97); always describing a momentous historical change),

- $\quad$ 'Germans were back on the' (72); always found in the context of war

- $\quad$ 'aspects crowded back on his' (60; a quote by Robert Luis Stevenson):

And now, as he lay in prison waiting the mortal push, these different aspects crowded back on his imagination with a new and startling significance; and he wrote a ballad, by way of epitaph for himself and his companions, which remains unique in the annals of mankind ...

- $\quad$ 'eyes went back on me' (44); mostly as part of the expression 'my eyes went back on me'

- $\quad$ 'colleagues look back on the' (43; all referring to memorable events; another quote by Robert Luis Stevenson among them). 
The BNC, however, yields the following contexts:

a) in the present

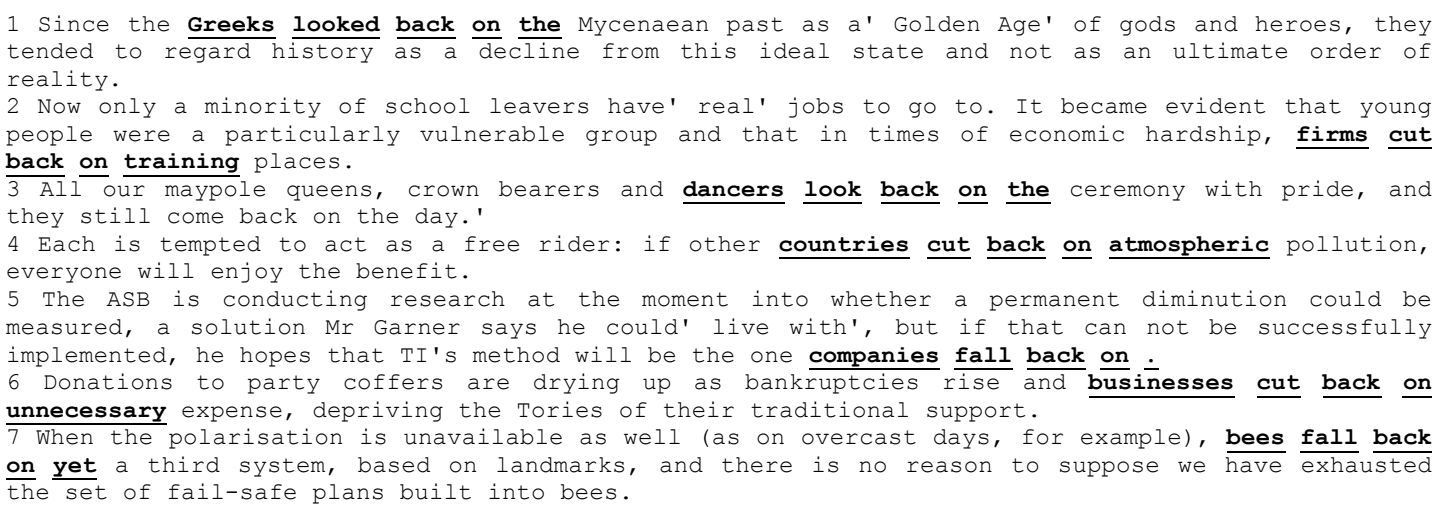

b) in the past



The case of the second grammatical string is not as clearly analysabe as that of the first. The actual lexical variable, 'cut', does appear in the BNC (a) in contexts 2, 4 and 6. In the first, it suggests an involuntary decision during 'economic hardship'. In the two others, the cutting back is viewed rather like a good idea. The phrasal verb 'fall back on', appearing in contexts 5 and 7, suggests a welcome solution to a problem. The use 'look back on' corresponds to what was observed in the Google Books corpora. The examples with the verb in the past are diverse and not really momentous. Google Books, on the other hand, showed a very interesting tendency of usage, despite (or more likely, because) coming from literary sources (the BNC literary sources apparently contain more trivial examples). Not only is there an ever present element of a significant transition, whether in the present or the past, but there was also a suggestion of death. This interestingly echoes the previous grammar string, where the BNC was the corpus affording suggestion of death or life danger. The subtext of both strings appears to interact. Both prospection and grammatical interaction have been observed in the opening of the text.

The case of the second grammatical string, studied for subtext in this section, is mirrored in many others in the studied text: certain semantic auras do appear, but without the actual lexical variable used in a particular case they appear too diluted to influence our interpretation of the studied text in a major way. Conveniently, the first two grammar strings could be viewed as end points of a cline observed when studying the Guardian text. At its one end, there are strings whose subtext is confirmed by contextual clues, and at its other end, there are strings whose subtext is too dependent on the states of affairs that are created by particular lexical items. Given that the text describes negative economic 
tendencies, it is no wonder that underprovision (i.e. negative fracture of semantic prosody, see Louw 2000 ) is observed. For example, the grammar string '*ing is *ed by' in 'domestic spending is dented by' mostly produced positive contexts of situation in both Google Books - UK and the BNC. Moreover, in the former corpus the contexts normally described a negative event caused, and not a positive tendency spoiled. The negative contexts in the BNC did not yield to generalisation due to few examples. The string 'the * will * *s' in 'the data will fan fears' also produced mostly positive contexts in both corpora, but negative ones did occasionally appear in both. On the other hand, in some cases the string's positive or negative aura matched the one discovered in the reference corpora. For example, 'had suffered from unsettled weather' ('had *ed from *ed *) had its match in 'had suffered from repeated attacks' as the only pattern found in Google Books - UK, and in 'had died from unrelated causes' appearing at the top of the frequency list in the BNC. Also, 'has been the main driver' ('has been the **er') yielded the pattern 'has been the prime mover' as the most frequent pattern in both corpora. All in all, the positivity/negativity aspect of the grammatical strings in the reference and their under- or overprovision could be observed in the text along with the role of the most frequent quasi-propositional variables (or subtext, see Louw, 2010) in some of its lines.

The following example will best illustrate the general behaviour of subtext in business texts (at least in the text studied for the purpose of this paper). Since the non-literal usages found here are used in business English, they cannot be expected to be found at the top of the frequency list for a certain grammar string. As for the most frequent lexis within a certain grammar string, it will have a bearing on the text's interpretation only if the other context clues also point in that direction (this mechanism in explained at more length in Louw and Milojkovic, 2014). For example, 'UK economic growth slowed in the first quarter of 2916' (*th *ed in the') yielded 'truth contained', death occurred', 'faith contained', 'truth revealed', growth occurred', 'truth embodied', 'truth expressed' etc. at the top of the Google Books - UK frequency list. More particularly, 'growth slowed' occurs at position 156 in Google Books - UK, and as the first string conforming to the pattern studied in the BNC. Judging by the context clues the Guardian text, the subjects of truth, faith, or death are never brought up (although death does appear, though briefly, in the subtext of the article's opening sentence). This stands in direct contrast to both Yeats's metaphors, whose subtext is confirmed by context clues throughout the poem. Additionally, some non-literal usages in the Guardian text were also shown to be further strengthened by relevant subtext, as was, for example, the first studied string, with 'results', 'observations' and 'findings' as some of the most frequent quasi-propositional variables (QPV). The opposition of truth, death or faith, on the one hand, and economic growth, on the other, brings us to the issue of a priori variables, established within a string in the course of time, as opposed to what Louw calls 'pagan' variables - more recent, more practical, more trivial (see the analysis of 'move him into the sun' in Louw and Milojkovic, 2015). Thus, taking into account the genre as such, it stands to reason that non-literal usages in business English texts will not as a rule overlap with their strings' most frequent lexis.

\subsection{Co-selection and relexicalisation}

Relexicalisation, or the gaining by a figurative expression of its literal meaning because of the proximity of other collocates, plays a huge part in the two Yeats's metaphors. Here they are, in their extended contexts, with the releixcalisers highlighted in italics:

My circus animals were all on show,

Those stilted boys, that burnished chariot,

Lion and woman and the Lord knows what.

A mound of refuse or the sweepings of a street, Old kettles, old bottles, and a broken can,

Old iron, old bones, old rags, that raving slut

Who keeps the till. Now that my ladder's gone, 
I must lie down where all the ladders start

In the foul rag and bone shop of the heart.

The highlighted relexicalisers do indeed recreate the realities of a circus and a rag-and-bone shop of Yeats's heart. However, 'circus animals' and 'ladder' are images freely chosen by the poet. We will never know how he came across these and not some other lexical items as vehicles for his selfexpression. They are not delexical in the proper sense, in which 'a sharp drop' or 'fan fears' in the text are delexical. According to Sinclair (Louw and Milojkovic, 2016; also personal communication, Bill Louw) any delexical expression will have at least two meanings, one of which literal and the other non-literal. As was previously stated, the purpose of the Guardian author must have been to describe economic tendencies as clearly as possible, for which purpose she used lexis commonly used in the chosen genre and whose meanings any dictionary will undoubtedly provide.

Still, we may find out, through co-selection, if any of the non-literal usages in the Guardian text are at any point relexicalised. For this purpose, COCA (Davies 2008-) is more appropriate than the Google Books corpus, as the former provides a better co-selection facility. 'Drop' co-selected with 'hit' yielded 8 contexts in the BNC:

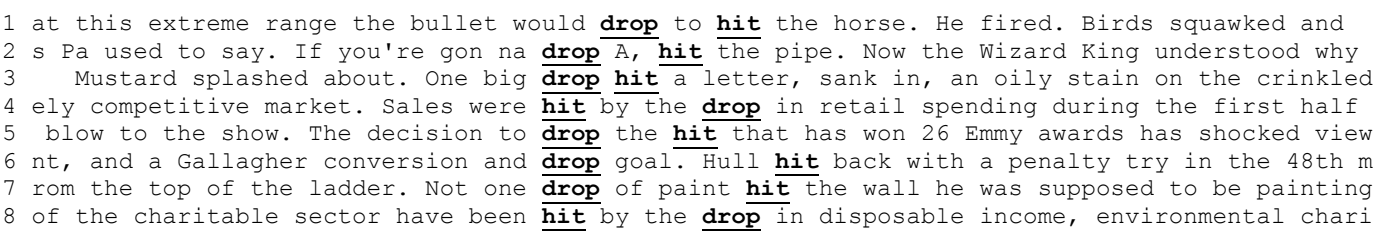

There are three contexts in which the co-selected items are used in their literal sense (contexts 1, 3, and 7). There are two contexts in which they are used precisely in the sense in which they appear in the Guardian text ('hit by the drop', contexts 4 and 8). In contexts 5 and 6 the usage is also delexical, albeit different in meaning. From this we may conclude that some degree of relexicalisation is certainly present, as such states of affiars do surface in the corpus, but contexts 4 and 8 also suggest that 'hit by the drop' is a standard non-literal expression with a precise meaning, used in business English. When it comes to 'a much sharper drop', the BNC contains 'a strikingly sharper drop in fertility', and 40 more cases of 'drop' co-selected with 'sharp'. The latter are all delexical, even though some of them do not come from the domain of business, but, for example, sociology and medicine. When 'drop*' was co-selected with 'dip*', the results in the BNC were as follows:

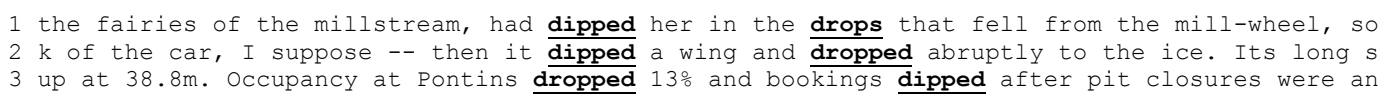

The first two lines contain 'dip' and 'drop' used literally, while the usage in the third context is delexical. Clearly, delexical use does not preclude relexicalisation in the reference corpus, even though the meaning of the delexical set phrase which is being relexicalised is known beforehand and cannot be brought into question, as in the case of 'The main drag came from food and clothing', with 'drag' and 'food' co-selected in the BNC:

1 Now, with new carts, he could $\underline{\text { drag }}$ both water and $\underline{\text { food }}$ to where they were needed.

The same can be said of 'face' and 'momentum' in 'the UK economy has lost momentum in the face of a slowdown':

1 In the added heat of the fire beads of sweat welled on her forehead, rolled down the furrows of her face and, gaining momentum, dropped weightily on to the ground. 
However, the macro-context of situation unambiguously points to the delexical nature of all the non-literal usages highlighted in the Guardian text. The delexical meanings give one another semantic support and reduce the words' potential to relexicalise to the minimum. Their familiarity to the reader and undisputed interpretation suppress any relexicalising powers their collocates (also delexical) might possess.

As for subtext, where it is confirmed by other context clues, as in the first string studied in this paper, co-selection also may be employed to give support to its role, as in 'results' and 'economy':

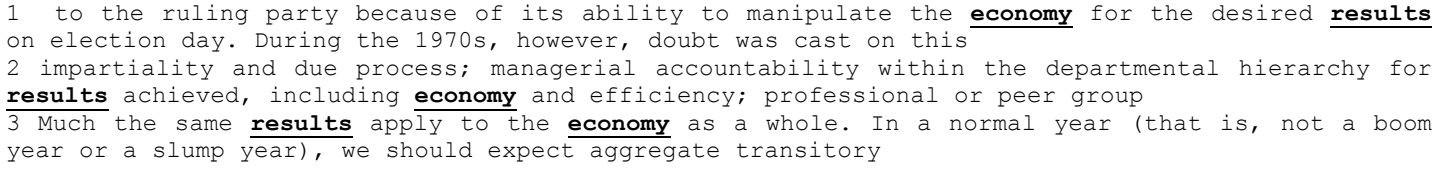

All in all, as the point of the Guardian text may be taken to present clear information, the nonliteral usages mentioned in this section, all of them delexical, do not have any implied meaning that involves and results in foregrounding, as in Yeats.

\subsection{A probable metaphor?}

Still, one particular pattern in the text might be said to approach Yeats's figurative language to a greater extent than the other delexical expressions. 'Households are getting a tighter hold on the purse strings' seems closer to figurative usage than 'had been hit by a drop', because, intuitively, it seems more descriptive. We have seen that 'hit by a drop' only appears in business contexts as a delexical expression. 'Tigher hold' and 'purse strings' seems to be a combination that is more susceptible to visualisation.

When 'purse' is co-selected with 'hold', the BNC is quick to dash such hopes:



All these usages are delexical. Perhaps the collocate 'tighter' makes the expression more literal? These are BNC contexts featuring 'tighter hold':

1 hit the post. Murphy, Mackenzie and Roberts took a tighter hold on midfield and wingers

2 nothing for the child with potential. \# Serbs take tighter $\underline{\text { hold }}$ of war gains \# AS the

These two are also delexical. Still, in COCA the only context available is literal:

1 downstairs. He breathes deeply, takes a tighter hold of Herbie's leash. Warily, he pushes

The Google Books - UK corpus yielded 340 instances of 'tighter hold', including the pattern 'tighter. Hold'. Of all the contexts actually available for close inspection, those that discussed health used the collocation literally, and those that discussed relations of power, whether political, hierarchical or personal, used it delexically. In fiction there were contexts such as

1 "It means you need to take a tighter hold on the reins and push him forward with your legs. 2 savagely yanked him upward in an even tighter hold. "Move!" Langford yelled to Gabriel.

Legal contexts did not preclude the literal use: 
3 plaintiff to testify that the reason she did not take a tighter hold of the railing was that she felt a little afraid of an electric shock, as she did not know what to expect

The subtext of 'are getting a tighter hold of the purse strings' (are *ing a *er *) is as follows:

\begin{tabular}{|l|l|r|l|l|}
\hline & BNC & & Google Books - UK & \\
\hline 1 & are taking a greater interest & 2 & are doing a better job & 849 \\
2 & are doing a better job & 2 & are taking a closer look & 204 \\
3 & are enjoying a better quality & 2 & are playing a greater role & 179 \\
4 & are becoming a better team & 1 & are having a harder time & 167 \\
5 & are attracting a larger following & 1 & are playing a larger role & 164 \\
\hline
\end{tabular}

The positive prosody of the string is apparent, and the lexical variables suggest better control and closer attention, as if the author approves of 'getting a tighter hold on purse strings'. Now that the delexical/relexicalised aspects of the author's wording, as well as its subtext, has been studied in detail, the next section will juxtapose it with Yeats's metaphors.

\subsection{Defining business English metaphors}

The survey in the preceding sections affords a clear idea of the transitions in business texts featuring non-literal usages. Before proceeding to define them in terms of metaphors, a juxtaposition between them and Yeats's metaphors will highlight their similarities and differences.

Households are getting a tighter hold on the purse strings

My circus animals were all on show

Now that my ladder's gone

It is the mechanism of relexicalisation that the difference between them as well as our future definition will hinge upon. 'Households', 'tighter hold' and 'purse strings' are delexical expressions, with particular meanings in business contexts. All these expressions also have literal meanings. Their literal meanings are cancelled out by the context. 'Hold' and 'purse strings', when co-selected, yield delexical uses in the BNC, but 'tighter' co-selected with 'hold' achieve a slight degree of relexicalisation in COCA and Google Books - albeit in other genres. In our chosen business English text, these relexicalisers are all used delexically. Moreover, the string involving these three expressions is clearly understandable on its own, without resorting to wider context. As for the subtext underlying 'are getting a tighter hold', it points to a bigger role and greater understanding households now have in controlling their financial affairs. The variables 'having a harder time' also point up the consumers' difficulties. If we take into account that the text speaks about the reduction of consumer spending, then the most frequent lexical variables in this grammatical string may be said to interact with the text as a whole.

'Circus animals' and 'ladder' are relexicalised by a considerable number of collocates whose meanings in the text are all literal. There is no register in which both these words acquire primarily and consistently delexical meanings. However, their literal meanings are only secondary in respect of authorial intention, as the focus of the poem is on their implied meaning ('circus animals' feature in the title). As previously stated, in the corpus, their implied meaning, 'literary devices', creates states of affairs of artistic creation through co-selection. In this, they differ hugely from 'tighter hold' and 'purse strings' whose delexical meaning is primary and only meaning. However, when it comes to subtext, the subtext of both 'circus animals' and 'ladder' interacts with contextual clues throughout the poem in a way that may be said to resemble that in the Guardian text. 
Therefore, business English metaphors are in fact delexical expressions that achieve a slight degree of relexicalisation through one another, because they may all easily attain their literal meanings in other registers. They do not attain any implied meanings in their surroundings; on the contrary, their delexical meanings are the primary message of the text. The subtext of the strings in which they are embedded interacts with the subtext of other grammatical strings and may be further confirmed by explicit context clues.

\section{Conclusion}

The research into non-literal usages present in the chosen Guardian business text proves that subtext plays a considerable role in the business register. This is apparent due to the mechanism of prospection, when the most frequent variables of a grammar string in fact announce future transitions, and in the fact that there may exist subtle interactions between particular QPVs of neighbouring grammar strings. Also, the semantic auras of certain grammar strings are fractured in the studied text, mainly towards negativity, which is consistent with the text's reporting negative tendencies in domestic economy, and which must contribute to the text's worried tone.

When it comes to whether these non-literal usages may be referred to as metaphors, the question is that of convention rather than essence. If we adopt the stance of Lakoff and Johnson (1980), this question should not have been asked in the first place. If we stick with terminology in existence prior to the cognitive revolution, then we have done well to compare these usages to the two original metaphors found in Yeats's 'The Circus Animals Desertion'.

The non-literal usages in the studied Guardian text are no exception to general usages of these expressions. They do not convey any implied meanings. Understanding them requires very little context (just what is enough for any word or expression, since uncontextualised expressions cannot be interpreted in principle). Furthermore, the clarity, precision, consistence and lack of ambiguity in their use reflect the intention of the author. Seeing as they are used in their primary and only meanings that are possibly interpretable in the given register (not context!), the jury is still out on whether our calling them metaphors at all contributes to our understanding of their role in the language. This article suggests that they be called delexical expressions.

\section{References}

Abrams, M. H. \& Harpham, G. G. (2009). A Glossary of Literary Terms. Boston:

Cudden, J. A. (1999). The Penguin Dictionary of Literary Terms and Literary Theory. London: Penguin Books

Davies, M. (2004-). BYU-BNC. (Based on the British National Corpus from Oxford University Press). Available online at http://corpus.byu.edu/bnc/

Davies, M. (2008-). The Corpus of Contemporary American English: 450 million words, 1990present. Available online at http://corpus.byu.edu/coca/

Davies, M. (2011-) Google Books Corpus. (Based on Google Books n-grams). Available online at http://googlebooks.byu.edu/

Hunston, S. (2007). 'Semantic Prosody Revisited', International Journal of Corpus Linguistics Vol. 12, No. 2, pp. 245-264.

Lakoff, G. and Johnson, M. (1980; new edn. 2003). Metaphors we Live by. Chicago: University of Chicago Press. 
LaPolla, R. J. (2006). The How and Why of Syntactic Relations. Invited plenary address and keynote of the Centre for Research on Language change Workshop on Grammatical Change at the Annual Conference of the Australian Linguistics Society, University of Queensland.

Louw, W. E. (2009). 'Consolidating empirical method in data-assisted stylistics: towards a corpusattested glossary of literary terms', In S. Zyngier, M. Bortolussi, A. Chesnokova and J. Auracher (eds.) Directions in Empirical Literary Studies. In Honour of Willie van Peer, Amsterdam: John Benjamins, pp. 243-264.

Louw, W. E. (2010). 'Collocation as instrumentation for meaning: a scientific fact', In W. van Peer, V. Viana, and S. Zyngier (eds.) Literary education and digital learning: methods and technologies for humanities studies, Hershey, PA: IGI Global, pp. 79-101.

Louw, W. E. and Milojkovic M. (2014). Semantic Prosody. In The Cambridge Handbook of Stylistics, P. Stockwell and S. Whiteley (eds), 263-280. Cambridge: CUP.

Louw W. E and Milojkovic M. (2015). Shared logical form or shared metaphysics: In search of corpus-derived empathy in stylistics. Procedia - Social and Behavioural Sciences 198, 535-545. Elsevier

Louw W. E. and Milojkovic M. (2016). Corpus Stylistics as Contextual Prosodic Theory and Subtext. Amsterdam: John Benjamins

Milojkovic M. (2016). 'Subtext as humour: Grammatical 'hidden meaning' as part of pun and metaphor in English', Studying Humour -International Journal (on line), Aristotle University of Thessaloniki, Vol. 3.

Milojkovic M. and Louw W. E (2016). Towards a corpus-attested definition of creativity as accessed through a subtextual analysis of student writing. In Key Competencs in English Medium Higher Education, Ed R. Breeze and C. Sancho Guinda. Springer

Mautner T. (2005). The Penguin Dictionary of Philosophy. London: Penguin Books.

McEnery, T. and Hardie, A. (2012). Corpus Linguistics. Cambridge: CUP

Simpson, P. (2014). Stylistics. Abington: Routledge

Stewart, D. (2010). Semantic prosody: a critical evaluation. London: Routlegde.

Xiao, Z. (2013) Review of McEnery and Hardie (2012) Corpus Linguistics: Method, Theory and Practice. Corpus Linguistics and Linguistic Theory 9(2): 293-303. 